\title{
Symptomatic neonates with Ebstein anomaly
}

Andreas Pflaumer, MD, ${ }^{a}$ Andreas Eicken, MD, ${ }^{a}$ Norbert Augustin, MD, ${ }^{b}$ and John Hess, MD, PhD, ${ }^{a}$ München, Germany

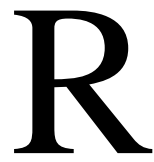

ecently there have been significant improvements in the diagnosis and treatment of Ebstein anomaly. Cyanotic neonates with Ebstein anomaly are the subgroup at highest risk. Total mortality rate exceeded $80 \%$ before 1986, and a mortality rate of $47 \%$ in 1986 to 1996 was reported by Yetman and colleagues. ${ }^{1}$ No standardized treatment protocol for these infants has been published in the literature. Early surgical intervention within the first days of life showed good outcome after a modified Starnes operation (closure of the tricuspid and pulmonary valve and an aortopulmonary shunt) in some recent reports. We present the case of a neonate with severe Ebstein anomaly and report on our treatment strategy.

\section{Clinical Summary}

Immediately after birth, the term neonate presented with severe heart failure and desaturation. Mechanical ventilation and prostaglandin E (PGE) infusion were started. Echocardiography (Figure 1) showed Ebstein anomaly with severe tricuspid and pulmonary valve regurgitation, a widely patent ductus arteriosus, and type II atrial septal defect with a right-to-left shunt. A mortality of approximately $40 \%$ was estimated by means of the echocardiographic score introduced by Celermajer and associates. ${ }^{2}$

After 6 weeks of intensive care treatment, pulmonary blood flow continued to be scarce. PGE infusion could not be discontinued. Cardiac catheterization showed functional pulmonary atresia, and arterial oxygen saturation persisted at levels less than $65 \%$.

A modified Starnes operation ${ }^{3}$ was performed, and the infant slowly recovered. Echocardiography showed some residual blood flow into the right ventricle, and left ventricular function had normalized. At the age of 7 months, the infant underwent a bidirectional Glenn procedure. Cardiomegaly declined, and transcutaneous oxygen saturation was $85 \%$. When the infant was 18 months old, a total cavopulmonary anastomosis was performed with an 18-mm extracardial conduit. The child rapidly recovered from both operations and is doing well now. The left ventricular size is close to normal, right-sided structures are small, and arterial oxygen saturation is more than $90 \%$.

\footnotetext{
From the Department of Pediatric Cardiology and Congenital Heart Disease $^{\mathrm{a}}$ and Department of Cardio-Thoracic Surgery, ${ }^{\mathrm{b}}$ Deutsches Herzzentrum, Technische Universität München, München, Germany.

Received for publication Sept 11, 2003; revisions received Oct 8, 2003; accepted for publication Oct 10, 2003.

Address for reprints: Andreas Pflaumer, MD, Kinderkardiologie, Deutsches Herzzentrum München, Lazarettstr. 36, D-80636 München, Germany (Email: Pflaumer@dhm.mhn.de).

J Thorac Cardiovasc Surg 2004;127:1208-9

$0022-5223 / \$ 30.00$

Copyright $\odot 2004$ by The American Association for Thoracic Surgery

doi:10.1016/j.jtcvs.2003.10.048
}

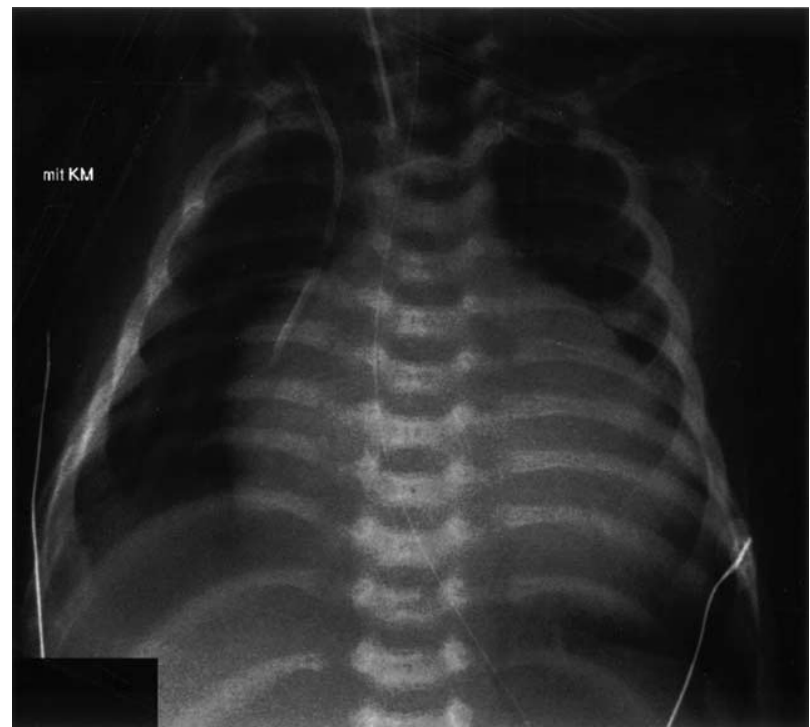

Figure 1. Chest x-ray film on day 28. Increased cardiothoracic ratio of 0.8; superior vena cava shifted to the right and decreased pulmonary vascular markings.

\section{Retrospective Review}

Since 1992, 17 symptomatic newborns with Ebstein anomaly have been admitted to our unit. Two newborns had additional complex heart disease and were excluded. Fifteen newborns with isolated Ebstein anomaly were included into further evaluation. Five patients had cyanosis and heart failure, 8 patients had cyanosis, and 1 patient had heart failure. Arrhythmia as the presenting symptom was observed in 1 patient, who only had mild cyanosis and moderate heart failure.

The median observation time was 6.6 years (0.1-11.5 years). A total of 13 of the 15 newborns needed PGE to support pulmonary blood flow. A Starnes operation in the first 6 weeks of life was performed in 3 patients during the first 6 weeks of life, 2 patients died ( 1 patient underwent operation in another hospital), and 1 patient is alive. In the other 9 patients, PGE could be weaned and an operation was postponed. Corrective surgery (tricuspid valvuloplasty creating a monocusp valve) was then performed in 6 patients aged 10 to 65 months (all alive) (Figure 2). Four patients are awaiting reconstructive surgery.

\section{Discussion}

Ebstein anomaly is associated with a high morbidity and mortality in symptomatic neonates. ${ }^{2}$ Looking at our data retrospectively, we observed that most symptomatic newborns with Ebstein anomaly benefit from declining pulmonary vascular resistance, which resulted in augmented pulmonary blood flow. In our group of patients with Ebstein anomaly who needed PGE, most patients im- 


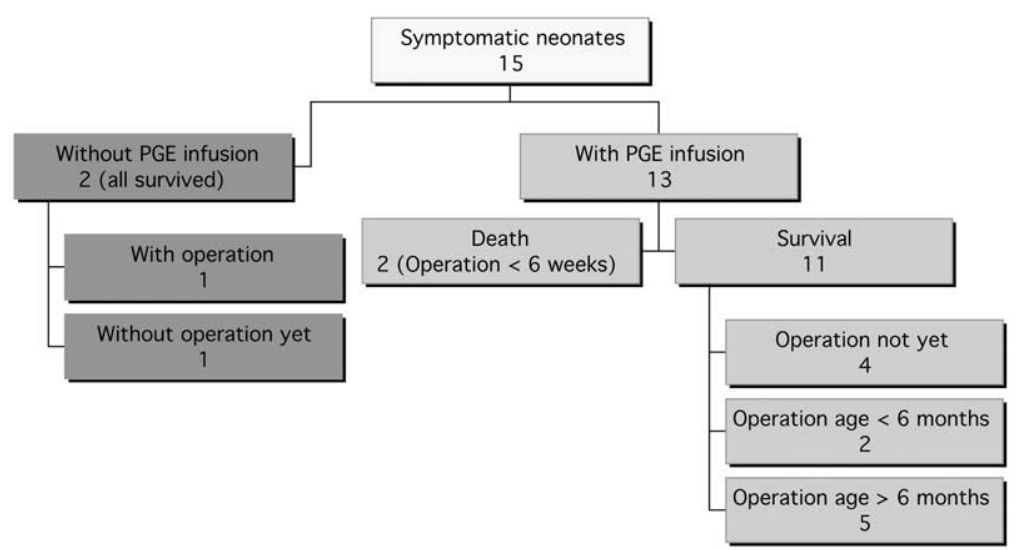

Figure 2. Flow chart of 15 newborn infants with Ebstein anomaly. PGE, Prostaglandin E.

proved within the first weeks, and an operation was postponed to childhood. Then surgical reconstruction of the tricuspid valve is possible and safe, and has a favorable long-term outcome. ${ }^{4}$

In contrast with our expectant approach, Knott-Craig and associates $^{5}$ vote for early monocuspid reconstruction of the valve, right ventriculorhaphy, subtotal closure of a type II atrial septal defect, and aggressive reduction atrioplasty. The short-term outcome is good, but the long-term outcome of this approach is not known yet.

van Son and colleagues ${ }^{6}$ suggest early univentricular repair within the first week of life. They treated 5 symptomatic newborns without early mortality. This treatment algorithm in all symptomatic newborns with Ebstein anomaly would have led to a univentricular heart condition in some patients, who could have been candidates for an early or late biventricular repair after physiological lowering of the pulmonary vascular resistance.

If the combination of severe tricuspid regurgitation and poor right ventricular function is present and declining pulmonary resistance does not lead to clinical improvement, operative intervention is indicated. The growing number of case reports referring to a successful modified Starnes operation shows that this operation can be performed. However, we strongly encourage an expectant approach in symptomatic neonates before a decision for surgical management is made.

\section{References}

1. Yetman AT, Freedom RM, McCrindle BW. Outcome in cyanotic neonates with Ebstein's anomaly. Am J Cardiol. 1998;81:749-54.

2. Celermajer DS, Bull C, Till JA, et al. Ebstein's anomaly: presentation and outcome from fetus to adult. J Am Coll Cardiol. 1994;23:170-6.

3. Starnes VA, Pitlick PT, Bernstein D, Griffin ML, Choy M, Shumway NE. Ebstein's anomaly appearing in the neonate. A new surgical approach. J Thorac Cardiovasc Surg. 1991;101:1082-7.

4. Augustin N, Schmidt-Habelmann P, Wottke M, Meisner H, Sebening F. Results after surgical repair of Ebstein's anomaly. Ann Thorac Surg. 1997;63:1650-6.

5. Knott-Craig CJ, Overholt ED, Ward KE, Razook JD. Neonatal repair of Ebstein's anomaly: indications, surgical technique, and medium-term follow-up. Ann Thorac Surg. 2000;69:1505-10.

6. van Son JA, Falk V, Black MD, Haas GS, Mohr FW. Conversion of complex neonatal Ebstein's anomaly into functional tricuspid or pulmonary atresia. Eur J Cardiothorac Surg. 1998;13:280-5. 